\title{
Mecanismo de control y defensa de la convencionalidad en el sistema procesal constitucional mexicano
}

\author{
Tlexochtli Rocío Rodríguez García \\ Doctora en Derecho Constitucional por la Universidad de Xalapa, México. Candidata a doctora en Derecho para el \\ Siglo XXI de la Universidad de Armería, España. Maestra en Derecho Constitucional y Amparo por la Universidad \\ Cristóbal Colón, México. Maestra en Docencia Universitaria de la Universidad de Xalapa, México. Especialista en \\ Docencia Universitaria por la Universidad de Xalapa, México. Docente de la Universidad Veracruzana, Universidad de \\ Xalapa y el Centro Mexicano de Estudios de Posgrados.Correo electrónico: tlexochtli@hotmail.com
}

\section{Resumen}

El presente ensayo tiene como objetivo brindar al lector un panorama acerca de la reforma constitucional del 11 de junio de 2011 en México, con la finalidad de que se logre sustentar la propuesta que se plantea, pues se cree que esta reforma no resulta suficiente para garantizar la protección a los derechos humanos, toda vez que la protección a estos derechos llega a un sistema procesal constitucional ya establecido, por ello, resulta necesario adecuarlo a las nuevas necesidades.

Se propone la incorporación de un mecanismo de control de convencionalidad al sistema procesal constitucional mexicano, como garantía de convencionalidad, con el que se podrá lograr la certeza jurídica que los gobernados necesitan saber que la protección a sus derechos humanos será garantizada a través de un mecanismo jurisdiccional.

Palabras clave: Derechos humanos, control de convencionalidad, Sistema Procesal Constitucional, cuestión de inconvencionalidad, control de convencionalidad.

\begin{abstract}
This essay aims, providing the reader an overview about the constitutional reform of 11 June 2011 in Mexico, with the aim of achieving an underlying the proposal arises, as it is believed that this reform is not sufficient to ensure the protection of human rights and protection whenever these rights comes to constitutional procedural system in place, so it is necessary to adapt to new needs.

The incorporation of a mechanism for control of compliance to constitutional procedural system Mexican, as a guarantee of compliance with which may achieve legal certainty that the citizens need to know that the protection of their human rights will be secured through a mechanism is proposed court.
\end{abstract}

Keywords: Human rights, conventionality control, process system constitutional, question of unconventionality, control of compliance.

\section{Résumé}

Cet essai vise, offrant au lecteur une vue d'ensemble sur la réforme constitutionnelle du 11 Juin 2011, à Mexico, dans le but qui est atteint soutien la proposition qui se pose, car on croit que cette réforme ne est pas assez pour assurer la protection des droits de l'homme, et que la protection de ces droits se agit de système procédural constitutionnel en place, par conséquent, il est nécessaire de se adapter aux nouveaux besoins . L'incorporation d'un mécanisme de contrôle du respect de l'ordre constitutionnel de la procédure Mexique, comme une garantie de la conformité, avec lequel vous pouvez obtenir une sécurité juridique que les citoyens ont besoin de savoir que la protection de leur garanti par un mécanisme des droits humains est proposé tribunal.

Mots-clés: Droits de l'homme, Le contrôle de conventionnalité, Système de processus constitutionnel, Question de anticonformisme, de contrôle de conformité. 



\section{Mecanismo de control y defensa de la convencionalidad en el sistema procesal constitucional mexicano*}

Tlexochtli Rocio Rodríguez García

\section{INTRODUCCIÓN}

Actualmente la protección de los derechos humanos ocupa un lugar muy importante en todos los países y México no puede retrotraerse de la protección a estos, es así que a raíz de la ratificación de los diversos instrumentos internacionales es que el Estado mexicano se ha comprometido a su defensa, por lo anterior es que el sistema mexicano ha incorporado explícitamente la protección de estos en el artículo primero constitucional, lo cual fue publicado en el Diario Oficial de la Federación el 10 junio de 2011.

Ahora bien, es cierto que la protección a los derechos del hombre resulta ser de gran importancia, pero también es relevante que México cuenta con un sistema jurídico que al incorporar la mencionada reforma viene a perturbar el sistema constitucional ya establecido; esto es así, puesto que con la incorporación de la protección de estos derechos se trastocan temas que tienen que ver con la competencia de juzgadores federales y locales.

De esta forma, si se quiere encontrar la manera más eficaz para llevar a cabo la protección de los derechos humanos, se debe considerar el sistema constitucional de México y, por supuesto, los mecanismos de control constitucional que el país ha adoptado para la defensa y control de la constitución, y esto, sin duda, solo se podrá entender desde la perspectiva del derecho procesal constitucional.

Así, en el desarrollo de este ensayo primero se deberá comprender el sistema jurídico que México ha adoptado, que se reconoce como de tipo "control concentrado", para así establecer qué es un mecanismo de control constitucional y para qué

El presente artículo se deriva del Proyecto de Investigación: Investigaciones jurídicas de aplicación social. Universidad Veracruzana, México. Cuerpo Académico Consolidado UV-CA-311 - Redes para el Desarrollo, Cultura, Ciencia y Tecnología en Transdisciplinariedad. 
sirve. Posteriormente, se busca conocer qué es la cláusula de convencionalidad o interpretación conforme, recién incorporada al Sistema Constitucional Mexicano $\mathrm{y}$, consecuentemente, se vislumbrará la tarea que hoy en día tienen los juzgadores en materia de derechos humanos al momento de resolver un determinado asunto, y se podrá discernir la problemática que se presenta con la incorporación de la convencionalidad.

Se señala como "incertidumbre jurídica” la función que desarrollan los juzgadores al resolver un litigio en el que se pueda relacionar con derechos humanos, asimismo, se analizará la propuesta de resolver el concepto con la incorporación de un medio de control constitucional denominado "Cuestión de inconstitucionalidad", que si bien no está dentro del sistema mexicano, se podría adoptar con algunos cambios que serán señalados a lo largo de la presente investigación.

\section{PROTECCIÓN DE LOS DERECHOS HUMANOS EN MÉXICO DURANTE EL SIGLO XX}

Como se señaló en el apartado anterior, los derechos humanos han tenido su nacimiento a lo largo de la historia en las diversas culturas, y en nuestro país su protección ha tenido notas características, que para el presente trabajo resultan de gran importancia, al menos mencionarlas, puesto que con ellas se podrá tener una mayor conciencia de las implicaciones que tiene y seguirá teniendo la reforma al artículo $1^{\circ}$ constitucional del pasado 1 de junio de 2011, ya que esta reforma fue el fruto de una larga lucha y por ello, es necesaria una buena regulación en la forma en que han de protegerse estos derechos.

Tenemos en principio que después de la época de la colonización y una vez que se consumó la Independencia, tras años de larga lucha, se llega a la época del Porfiriato, momento en el que, a pesar de que se dice se logró grandes progresos, no sucedió lo mismo en el desarrollo que debía tener la protección a los derechos humanos.

Es así que hacia 1900 Porfirio Díaz es reelecto por última vez, sin embargo, comienzan a surgir los movimientos de oposición; así para 1903 se convoca el partido liberal y surge el "Club antireleccionista", que significaba una pugna entre intelectuales; en tanto en el campo era evidente el descontento y la desigualdad que se vivía y lo mismo acontecía con los obreros en proceso de la industrialización; por el contrario, la autoridad se encargaba de reprimir al obrero cuando había algún intento de huelga" (Martínez, 1998, p. 134).

Por ello, el movimiento armado de 1910 tiene orígenes complejos, "pues comprende además de los ya mencionados otros más, pero como motivos principales podemos decir que: se encuentra la lucha contra la injusticia, y el tema de la propiedad de la tierra" (Carbonell, 2012, p. 231).

La Constitución que hasta ese entonces se encontraba vigente era la de 1857 la cual tenía una aplicación práctica pero muy limitada. Ahora bien, una vez que se logró la revolución y se constituyó el Congreso en Querétaro es que nace la Constitución de 
1917, y que desde entonces sigue vigente; en esta se consagraron muchas novedades, como por ejemplo: a) la ampliación del catálogo de Fundamentales, como es el caso del derecho a la educación, el derecho al debido proceso, el principio de debido proceso entre otros, todos ellos contenidos en el capítulo denominado "De las garantías individuales" hoy titulado "De los derechos humanos y sus garantías", b) "la inclusión de los llamados derechos sociales y por lo cual la Constitución mexicana fue la pionera, pues aquí se incluye el derecho al trabajo, así como la regulación de la propiedad de las tierras" (Carbonell, 2012, p. 231).

Posteriormente, se incorporaron otra clase de derechos sociales como el derecho a la vivienda, a la salud; pero en opinión de Carbonell y de otros autores se dice que estos derechos fueron vistos como simples "Normas programáticas, puesto que únicamente se indicaba un objetivo público que se debía seguir, pero que no suministraba una posición jurídica concreta para ninguna persona" (Carbonell, 2012, p. 278).

En otras palabras, estos derechos sociales fueron considerados antes de las reformas del 11 de junio de 2011 como normas constitucionales de eficacia indirecta, puesto que no eran aplicadas por sí mismas, sino que únicamente fijaron un objetivo que los órganos constitucionales debían alcanzar, que en su caso fue la protección a la clase obrera y campesina por mencionar algunos, y que requieren de la intervención de órganos estatales para satisfacer sus fines (Guerrero, 2012, p. 176).

Después de la promulgación de la Constitución de 1917, el desarrollo de los derechos humanos fue casi nulo, pues después de que México hiciera un gran aporte al mundo con la incorporación de los derechos sociales, no se volvió a tener ningún avance hasta los años ochenta, cuando se vio un pequeño movimiento al reformarse el artículo 3. Además, en lo jurídico se dio el cambio de nombre al capítulo primero por el "De las garantías individuales", denominación que estuvo vigente hasta el año 2011, por lo que prácticamente se desterró la noción de derechos humanos del léxico jurídico mexicano al incorporase el de "garantías individuales", ya que resultaba ser más práctico, aunque este término ha traído como consecuencia que se mal entienda este concepto (Martínez, 1998, p. 134).

Ciertamente el Estado mexicano ha tenido una incorporación muy lenta de los derechos humanos a su derecho interno, pese a que en su intervención internacional ha sido muy activo, pues participó en la formulación de muchos instrumentos internacionales, como lo fue la declaración Universal y la Declaración Americana; el problema durante años ha sido cuando se trata de asumir compromisos. Por tanto, aunque se habían ido incorporando a nuestro texto constitucional algunos derechos que le han permitido tener un toque de modernidad, lo cierto es que no han pasado de ser meros elementos decorativos, ya que no tenían una protección real.

Martínez (1998) ha señalado que ello acontece por:

Porque no había existido sino hasta recientemente una demanda de la sociedad por la vigencia de los derechos humanos y ello se puede corroborar cuando citamos, 
por ejemplo, el caso de Radilla Pacheco llevado a la Corte Interamericana y del cual derivaron para el Estado mexicano diversas obligaciones (p. 167).

Para el año de 1980, México ratificó siete instrumentos muy importantes, tanto de la ONU como de la Organización de Estados Americanos (OEA). Sin embargo, y pese a que no estuvo dispuesto a adoptar ningún mecanismo de control sobre la vigencia interna de los derechos humanos, se hizo muy notable durante el gobierno del expresidente López Portillo, pues este señalaba que la competencia de la Corte Interamericana estaba fuera de lugar en ese momento, toda vez que la legislación nacional preveía los recursos necesarios para corregir cualquier falla (Martínez, 1998).

Lo anterior, puede considerarse como un mero pretexto para no aceptar los cambios necesarios para la protección de los derechos humanos, además, en su tiempo se interpretó que solo se aceptaría la jurisdicción de la corte interamericana cuando las cosas en México salieran mal. No obstante, debe reconocerse que con la incorporación de los instrumentos internacionales señalados se dio la oportunidad de agregar nuevos derechos a nuestra Carta magna.

Y de ahí nos situamos hasta el 5 de junio de 1990 con la creación en forma del Ombudsman (defensor del pueblo) mexicano y aparece la Comisión nacional de Derechos Humanos (CNDH); sin embargo, este organismo no tenía muy claro su objetivo por lo que en principio no tuvo gran relevancia hasta ahora con las nuevas reformas (CNDH).

Por lo anterior, académicos como Martínez (1998) han señalado que

La aparición de la CNDH no fue un acto voluntarioso del entonces presidente Carlos Salinas sino que se trató de una exigencia social por el respeto de los derechos humanos destinada a la creación de defensa de derechos humanos frente al gobierno (p. 98).

Aunque se criticó mucho la creación y funcionamiento de la CNDH, puesto que sus resoluciones no eran vinculantes, lo cierto es que fue un notable avance para la protección de los derechos humanos, ya que antes de la creación de este organismo no se reconocía ni siquiera la posibilidad de ser susceptible de violación a estos derechos y menos aún sancionar a los responsables de dichas violaciones.

Otra forma de proteger a los derechos humanos se dio con la reforma de diciembre de 1994 cuando se incorporó a

La Constitución las acciones de inconstitucionalidad, que como ya se mencionó en el capítulo anterior, son un mecanismo de defensa de la Constitución y al mismo tiempo de los derechos humanos, puesto que permite a la SCJN ejercer un control abstracto de la leyes e incluso sobre tratados internacionales (Carbonell, 2012, p. 298).

Ahora bien, es evidente que la protección a esta clase de derechos fue mínima a pesar de que México tenía actividad en el derecho internacional, sin embargo, y como se ha venido mencionando, no fue sino hasta junio de 2011 cuando el sistema jurídico 
mexicano tuvo un gran movimiento con la reforma al artículo 1 constitucional y en general al primer capítulo de su constitución.

Lo anterior, porque esta reforma trajo consigo múltiples implicaciones a varios niveles, ya que los derechos y sus obligaciones no están dirigidos solo a los jueces, magistrados o ministros del poder judicial, sino a todos los integrantes de los otros poderes y esto implica los niveles federal, local y municipal.

\section{CARACTERÍSTICAS DE LOS DERECHOS HUMANOS}

Una vez establecido cómo han evolucionado los derechos humanos en México es necesario señalar las características que los distinguen; en la doctrina como en los instrumentos internacionales, podemos mencionar los siguientes:
a. Universalidad
b. Historicidad
c. Progresividad
d. Aspecto protector
e. Indivisibilidad
f. Eficacia directa (Carpizo, 2011, p. 168).

En cuanto a la Universalidad, se puede decir que significa "que todo ser humano posee una serie de derechos con independencia del país en que haya nacido o habite. Y así quedó plasmado en la Declaración Universal de los Derechos Humanos y en los pactos de la ONU de 1996" (Carpizo, 2011, p. 176).

La universalidad hace énfasis en que la cuestión de los derechos humanos no es solo un asunto de cada Estado, sino de la comunidad internacional. Por esta razón, las declaraciones de derechos humanos en las nuevas constituciones o en sus reformas son más parecidas entre sí. Por otra parte, el reconocimiento de los derechos humanos como exigencias éticas también sostiene la idea de universalidad, así esta característica está muy relacionada con la esencia jurídica natural y moral (Vásquez, 2011, p. 154). Además, el principio de universalidad sobrelleva un proceso de contaminación, nutrición y renovación de los derechos humanos producto de su propia expansión (Vásquez, 2011, p. 187).

En cuanto a la característica de historicidad se puede decir que "esta se complementa de la de universalidad, puesto que esta se refiere a tres aspectos: a) la evolución de la civilización; b) nuevos problemas necesidades y retos; y c) el contexto socio cultural de cada país" (Carpizo, 2011, p. 201).

En cuanto a la característica de la progresividad "implica tanto gradualidad como progreso, la primera se refiere a que la efectividad de los derechos no va lograrse" (Carpizo, 2011, p. 234). Además, el principio de progresividad supone la obligación a cargo de los estados de crear indicadores para poder verificar efectivamente el avance progresivo de los derechos. 
La característica de progresividad implica que en su concepción y protección, ya sea nacional o internacional, se vaya ampliando irreversiblemente el número y contenido de los derechos (Carpizo, 2011, p. 245). Por lo cual debe decirse que el principio de progresividad y el de no regresividad "están directamente relacionados con el estándar del máximo uso de recursos disponibles, por lo que si en el texto constitucional no se menciona deben entenderse comprendidos como parte del derecho internacional" (Carpizo, 2011, p. 250).

Por anterior, se considera que ambos principios deben suponerse importantes y por los cuales muchos Estados, incluyendo al nuestro, han tenido que adaptarse a las nuevas exigencias en la protección a los derechos humanos.

En cuanto a la característica de indivisibilidad implica que todos los "derechos ya sea civiles, políticos, económicos, sociales forman una unidad. Entonces, resulta claro que los derechos humanos son interdependientes entre sí, ya que unos se apoyan en los otros para integrar una unidad o bloque" (Carpizo, 2011, p. 253), una sola construcción; lo que sucede es que indivisibilidad

No sólo corre para la realización de los derechos sino también respecto de su violación, de tal forma que debe tratarse de situar los derechos inmediatamente violados con los derechos de los que depende y con los derechos cuya violación se desató el último agravio (Vásquez y Serrano, 2011, p. 234).

Respecto a la característica del aspecto protector se "refiere a que se debe amparar a toda persona humana, en virtud de que hasta el más poderoso puede llegar a necesitarlo" (Carpizo, 2011, p. 345), es decir, esta característica implica el más amplio aspecto de protección para todos los seres humanos sin importar su estatus.

En lo que concierne a la eficacia directa, significa que los derechos humanos reconocidos en la Constitución y en los instrumentos internacionales ratificados por un país vinculan obligatoriamente a todos los poderes públicos. Esta característica responde al principio de jerarquía de normas en un orden jurídico (Carpizo, 2011, p. 265).

Las características antes apuntadas las poseen todos los derechos humanos de acuerdo con lo que dispone la Sección I, párrafo 5 de la Declaración y Programa de Acción que procede de la Conferencia Mundial de Derechos Humanos de 1993, celebrada en Viena y que dispone que:

Todos los derechos humanos son universales, indivisibles e interdependientes y están relacionados entre sí. La comunidad internacional debe tratar los derechos humanos en forma global y de manera justa y equitativa, en pie de igualdad y dándoles a todos el mismo peso.

Ahora bien, a fin de cumplir con las obligaciones internacionales, México al realizar la ya multicitada Reforma del $1^{\circ}$ de junio de 2011 incorporó a nuestra Constitución los principios de universalidad, interdependencia, indivisibilidad y progresividad. Sin embargo, no puede negarse que los omitidos forman parte inseparable de los derechos humanos. 


\section{LA OBLIGATORIEDAD DE LOS INSTRUMENTOS INTERNACIONALES SOBRE DERECHOS HUMANOS}

Una vez que se han establecido las características de los derechos humanos es necesario hacer referencia al peso que los instrumentos internacionales sobre derechos humanos tienen del Sistema jurídico mexicano.

Pues bien, la primera cuestión por resolver es la situación que acontece cuando los derechos humanos "no tienen positivación, es decir, un marco normativo que los precise, así tenemos que en la historia se ha visto que para que se pueda tutelar un derecho determinado debe estar escrito aunque hay sus excepciones" (Gozaíni, 2000, p. 165).

El marco documental de los instrumentos internacionales tiene cuatro documentos básicos: "la Declaración Universal de los Derechos Humanos (París, 1948), la Declaración Americana de los Derechos y Deberes del Hombre (Bogotá, 1948), el Pacto Internacional de Derechos Civiles y Políticos de 1966 y la Convención Americana sobre Derechos Humanos de 1969" (Gozaíni, 2000, p. 178).

Aunque debe mencionarse que además de los señalados no obstante, estos han sido considerados como básicos. De esta manera, los derechos de los tratados han sido codificados de forma amplia en la Convención de Viena sobre Derechos de los Tratados de 1969, este ordenamiento entró en vigor en 1980 y ha sido ratificado por un número importante de Estados y se considera que sus disposiciones tienen el carácter de autoridad en materia de derecho de los tratados, aun para aquellos Estados que no son parte de esta.

Ahora bien, es importante aquí mencionar que México firmó la Convención el 23 de mayo de 1969 y desde el 25 de septiembre de 1974 ratificó la Convención de Viena. En este sentido, este ordenamiento resulta vinculante aun para el Estado que lo ha ratificado, y esto es porque sus disposiciones forman parte del Derecho Internacional consuetudinario.

De acuerdo con el artículo 2 de la Convención de Viena, "un tratado internacional es todo acuerdo internacional celebrado por escrito entre Estados y regido por el Derecho Internacional, ya conste en un instrumento único o en dos o más instrumentos y cualquiera que sea su denominación particular". De lo señalado se puede decir que se desprenden los elementos fundamentales de un tratado internacional:

a) la voluntad de los Estados para obligarse bajo los términos del tratado;

b) la concurrencia de voluntad de por lo menos dos partes; c) la intención de producir efectos legales; y d) que el acuerdo debe regirse por el derecho internacional (Barrena y Montemayor, 2001, p, 230).

Por otra parte, debe aclararse que los tratados se rigen bajo el principio fundamental según el cual estos son vinculantes entre las partes y deben ser cumplidos bajo el principio de buena fe y se materializa en el principio Pacta Sunt Servanda. Ahora bien, de acuerdo con el artículo 18 de la Convención de Viena la sola firma de los tratados previa su ratificación genera obligaciones internacionales, como son: 
Un Estado o una organización internacional deberá abstenerse de actos en virtud de los cuales se frustren el objeto y el fin de un tratado:

a) Si ese Estado o esa organización ha firmado el tratado o a canjeado los instrumentos que constituyen el tratado a reserva de ratificación, de un acto de confirmación formal, de aceptación o de aprobación, mientras ese Estado o esa organización no haya manifestado su intención de no llegar a ser parte en el tratado; o b) si ese Estado o esa organización ha manifestado su consentimiento en obligarse por el tratado durante el período que preceda a su entrada en vigor y siempre que esta no se retarde indebidamente.

Una manera de asegurar el cumplimiento de estas obligaciones es el permitir en el marco de la Constitución la aplicación provisional de los tratados. El sistema de incorporación "de nuestra constitución no prevé ningún principio que limite los poderes del Estado de acuerdo con el artículo 18 de la Convención referida, ni tampoco una regla que faculte al Estado la aplicación provisión de un tratado".

Así debemos decir que con fundamento en la Convención de Viena, el Estado no puede excusarse del incumplimiento de las obligaciones que haya contraído, como es el caso de los tratados que México ha ratificado en materia de derechos humanos, puesto que cuando ha dejado de cumplir con obligaciones le han generado responsabilidades que se han materializado en las sentencias en las que el Estado mexicano ha resultado condenado.

Por ello, es que el problema del incumplimiento generará siempre responsabilidad internacional del Estado. "Este problema es de gran importancia, ya que hace inoperante la acción de inconstitucionalidad a posteriori, porque la responsabilidad internacional en la que incurra México no es excusable por invocar normas internas" (Barrena y Montemayor, 2001, p. 1).

\section{LA REFORMA AL ARTÍCULO PRIMERO CONSTITUCIONAL}

La reforma constitucional en materia de derechos humanos publicada el 10 de junio de 2011 en el Diario Oficial de la Federación, es la más trascendental modificación a nuestra Constitución, tan importante e impactante es esta reforma, que si regresáramos a los momentos más importantes de la historia de nuestra Carta magna la podríamos equiparar al momento en que por primera vez en 1917 el texto constitucional de nuestro país incorporó los llamados derechos sociales.

En este orden de ideas, el impacto que tiene esta reforma no es solamente de forma sino que afecta al núcleo central de lo que son los derechos humanos. Ahora bien, debido a que es tan importante esa reforma es que se consideró la necesidad de realizar algunas reflexiones en torno a la manera en que la reforma constitucional ha transformado el marco normativo de nuestro sistema.

Así se puede decir primordialmente que esta reforma trajo consigo transformaciones al sistema jurídico mexicano y que según la opinión del Ministro 
Juan N. Silva "estamos ante un verdadero cambio de paradigma en nuestro derecho, y en segundo lugar trajo consigo grandes exigencias a la labor jurisdiccional, desde la forma en cómo se interpretan tanto los preceptos normativos sustantivos como los adjetivos" (Silva, 2013, p. 243).

Además, en la reforma sobresale el cambio de la denominación del Capítulo I de la Constitución, ya que deja el "De las garantías individuales"; la nueva denominación es considerada por algunos doctrinarios como Carbonell "una expresión mucho más moderna que las garantías individuales y es la que se suele utilizar en el ámbito del derecho internacional", aunque también señala que lo más atinado hubiese sido utilizar la denominación de "Derechos fundamentales", postura con la que de laguna forma comulgo, sin embargo, se cree que "el tan solo hecho de cambiar la denominación a derechos humanos es más precisa y no ocasionará en lo sucesivo mayores confusiones" (Carbonell, 2012, p. 89).

En efecto la nueva redacción del artículo primero constitucional cambió no solo en la proporción de su redacción (ya que pasó de tener tres párrafos a tener cinco), sino que conlleva implicaciones que hoy todavía permanecen inconmensurables, así el nuevo artículo $1^{\circ}$ reza de la manera siguiente:

Artículo $1^{\circ}$. En los Estados Unidos Mexicanos todas las personas gozarán de los derechos humanos reconocidos en esta Constitución y en los tratados internacionales de los que el Estado Mexicano sea parte, así como de las garantías para su protección, cuyo ejercicio no podrá restringirse ni suspenderse, salvo en los casos y bajo las condiciones que esta Constitución establece.

Las normas relativas a los derechos humanos se interpretarán de conformidad con esta Constitución y con los tratados internacionales de la materia, favoreciendo en todo tiempo a las personas la protección más amplia.

Todas las autoridades, en el ámbito de sus competencias, tienen la obligación de promover, respetar, proteger y garantizar los derechos humanos de conformidad con los principios de universalidad, interdependencia, indivisibilidad y progresividad. En consecuencia, el Estado deberá prevenir, investigar, sancionar y reparar las violaciones a los derechos humanos, en los términos que establezca la ley [...].

Como se puede observar el primer párrafo señala que en México todas las personas gozan de los derechos humanos reconocidos en nuestra constitución y en los tratados internacionales que México sea parte, como es evidente la protección resulta ampliada y se realiza un cambio de terminología, cambio al que hemos venido aludiendo, puesto que ya no utiliza más el término de garantías individuales, sino que ahora los llama derechos humanos.

Además, se habla aquí de un reconocimiento de los derechos, es decir, se vuelve derecho positivo este concepto. En palabras del ministro Silva esta transformación en el modo de concebir a los derechos significa que: 
Las personas no le deben ninguna clase de reverencia o sumisión alguna al Estado por que les concede graciosamente sus derechos, sino que se sirven de las instituciones estatales y del derecho para que se les reconozcan los derechos. Lo cual resulta ser un cambio de cultura también (Silva, 2013, p. 123).

Otro aspecto que es trascendente es la separación que se hace de los derechos y sus garantías, esto por que tradicionalmente se había asociado a ambos y hasta de alguna forma confundido unos con otros, cuando ya se ha visto que las garantías serán aquellos remedios procesales por medio de los cuales las personas harán respetar sus derechos.

Otra aportación es que los derechos que gozan las personas no se limitan a los contenidos en los 136 artículos de la Constitución, sino que se expanden a los tratados de que México sea parte. En otras palabras, tratándose de derechos humanos del texto constitucional se ha abierto para incluir con idéntica fuerza normativa disposiciones de fuente internacional sobre la materia, lo que da pauta para afirmar la presencia en nuestro sistema jurídico de un bloque constitucional extenso (Silva, 2013, p. 129).

Por último, respecto del primer párrafo también podemos señalar que al establecer que no podrá restringirse ni suspenderse, salvo en los casos y bajo las condiciones que esta Constitución establece, hace que su suspensión no tenga cabida salvo los casos y bajo las condiciones que el propio texto señale.

En cuanto al párrafo segundo se tiene que este recoge la figura de la interpretación conforme, al señalarse que todas "las normas relativas a derechos humanos se deberán interpretar a la luz de la protección constitucional y de los tratados internacionales" (Carbonell, 2012, p. 245).

Lo cual resulta ser una guía para los aplicadores de las normas jurídicas, además de que se invoca el denominado principio pro persona. Este principio supone que cuando:

Existan distintas interpretaciones posibles respecto de una norma jurídica se deberá elegir aquella que más proteja al titular de un derecho humano; asimismo, cuando en un caso concreto se puedan aplicar dos o más normas jurídicas el intérprete debe elegir aquella que igualmente proteja de la mejor manera al titular de ese derecho (Castellá y Expósito, 1993, p. 67).

Continuando con el tercer párrafo encontramos que las obligaciones de las autoridades mexicanas en materia de derechos humanos deberán cumplirse a la luz de los principios de universalidad, interdependencia, indivisibilidad y progresividad. Lo anterior significa que debe respetarse la universalidad de los derechos humanos, es decir, que estos son para todos sin ninguna clase de distinción o limitación, así mismo, que estos serán interdependientes unos de otros y que no se podrán dividir.

En lo que concierne al principio de progresividad, y que ya en apartados anteriores hemos señalado, se cree que este es uno de los más importantes, puesto que de su éxito dependerá la efectiva protección de los derechos humanos, ya que se deben 
establecer mecanismos efectivos que hagan avanzar la protección de estos derechos y que no haga que se queden incorporados a la Constitución como meras normas programáticas, por lo cual se considera que se debe poner especial atención.

Por otra parte, también se cree oportuno mencionar que si bien en la Constitución no se reconocen los demás principios que en derecho internacional caracterizan a los derechos humanos, ello no excusa de modo alguno no cumplir con estos. Puesto que como señala el ministro Silva (2013, p. 178) "esto no se trata de deberes morales, sino que se está en presencia de obligaciones jurídicas, todas igualmente exigibles y justiciables, con la finalidad primordial de combatir la violación impune de los derechos humanos".

El mismo párrafo tercero refiere que el Estado deberá prevenir, investigar, sancionar y reparar las violaciones a los derechos humanos, en los términos que establezca la ley. Así, investigar violaciones implica también sancionar violaciones de derechos. No obstante, para ello se necesita contar con lineamientos que le digan al juzgador en su caso cómo ha de ser el procedimiento; sin embargo, dicho procedimiento aún no existe, puesto que lo único que podría mencionar al respecto serían los mecanismos no jurisdiccionales y que se llevan a cabo mediante el ombudsman, pero no así en los procedimientos jurisdiccionales, esto aclarando que aún tienen algunos problemas en cuanto a la fuerza coercitiva de sus resoluciones.

Sobre el tema encontramos que México necesita recursos judiciales que permitan llevar ante los tribunales las violaciones de los derechos humanos, pues como bien lo señala Carbonell (2012, p. 80) "no basta con los recursos previstos para reparar la violación de otros derechos, cuando por sus características impidan el planteo adecuado del caso". Es muy relevante considerar la idoneidad de los recursos judiciales existentes, ya que no puede considerarse como cumplida por los Estados parte esa obligación, aduciendo que existen las vías tradicionales en caso de violación como es el caso de México, que durante años optó por esa postura.

Lo anterior, porque "los recursos judiciales existentes fueron diseñados para proteger cierto tipo de derechos, por lo que tienen enormes problemas al momento en que se le pide que sirvan para proteger" (Carbonell, 2012, p. 98), además, que lo señalado se encuentra en relación directa al principio de progresividad, ya que de esta se desprende la prohibición de la regresividad como una obligación, lo que significa que los Estados parte no pueden dar marcha atrás en los niveles alcanzados de la protección de estos derechos.

En síntesis se puede decir que en este tercer párrafo existen en esencia tres problemas que México enfrenta:

a) El señalamiento de las obligaciones, a cargo de todas las autoridades del Estado mexicano de promover, proteger, respetar y garantizar los derechos; b) el referente a los principios de interdependencia indivisibilidad y progresividad que se han mencionado; y c) se refiriere a lo que debe hacer el Estado mexicano cuando se presenten violaciones de derechos, es decir, prevenir, investigar, sancionar y reparar (Carbonell, 2012, p. 134). 
En cuanto a las obligaciones, se encuentra que no puede ser alegada la división vertical de los órdenes de gobierno como excusa para dejar de cumplir con esas obligaciones, es de acuerdo con lo que dispone el artículo 28 de la convención americana de Derechos Humanos (Pacto de San José). De lo cual se tiene que la misma obligación de cumplir con la protección de los derechos humanos tienen tanto las autoridades federales como locales.

\section{INCORPORACIÓN DE LA CLÁUSULA DE CONVENCIONALIDAD AL ARTÍCULO PRIMERO CONSTITUCIONAL}

Como se puede observar del apartado anterior, la reforma constitucional del 10 de junio de 2011 tuvo múltiples implicaciones, no obstante, para los objetivos de este trabajo es necesario hacer énfasis al control de convencionalidad, que si bien será objeto de estudio del siguiente apartado, lo cierto es que debe reseñarse su incorporación al nuevo artículo primero constitucional. Puesto que el control de convencionalidad es uno de los puntos culminantes del artículo primero, ya que se trata de una manifestación que anuncia un gran cambio de época para los juristas mexicanos.

El control de convencionalidad es consecuencia directa del deber de los Estados de tomar todas las medidas que sean necesarias para que los tratados internacionales que sean firmados se apliquen efectivamente (Carbonell, 2012).

Lo anterior, resulta además una consecuencia del artículo $1^{\circ}$ de la Convención Americana de Derechos Humanos y que establece que los estados partes se comprometen a respetar los derechos que ella establece, pero también a garantizar su pleno y libre ejercicio.

Ahora bien, la cláusula de convencionalidad o mejor llamada Cláusula de interpretación conforme, que es como la denomina Ferrer Mac-Gregor (2012, p. 123) es una manera de constitucionalizar el derecho internacional de los derechos humanos. Esta cláusula se encuentra en el párrafo segundo del nuevo artículo primero constitucional y que apunta que las normas relativas a los derechos humanos se interpretarán de conformidad con la Constitución y con los tratados internacionales, favoreciendo en todo monumento a las personas.

Esto hoy en día se convierte en una obligación para las autoridades, los legisladores y los jueces. De tal suerte que siempre que se trate de una norma en materia de derechos humanos tenemos que acudir a esta cláusula. En este sentido, los legisladores tendrán que "adecuar la normatividad utilizando este criterio y la administración pública debe ajustar su actuación conforme a la nueva pauta interpretativa en este artículo, ya que los destinatarios somos todos" (Ferrer, 2012, p. 154). En tales circunstancias esta cláusula resulta ser obligatoria, sin embargo, esto aún no se ha asimilado del todo pero es muy importante cumplirla.

Lo anterior es relevante para crear una práctica sistemática y constante de dicha técnica interpretativa en todos los niveles de gobierno, evitando con ello como lo 
denomina Ferrer (2012, p. 245) su utilización "esporádica" en detrimento de la efectividad y cultura de los derechos humanos y esto constituye un "deber" y no puede nunca ser "optativo" o "facultativo" para el intérprete de la norma.

Además, se debe señalar que el objeto de esta cláusula de interpretación no resulta restrictiva solo a los derechos que se encuentra expresamente señalado en la Constitución, sino también aquellos contenidos en los tratados internacionales, así como también se deben incluir las normas que en menor jerarquía a la Constitución los contengan como en toda norma sustantiva y adjetiva que sea parte de ordenamientos que existan en el sistema jurídico mexicano.

Así mismo, la expresión tratados internacionales que existe en la cláusula en mención contiene una "connotación amplia del término que le otorga el artículo 2.1.a). de la Convención de Viena sobre el Derecho de los Tratados vigente en México a partir del 27 de enero de 1980" (Ferrer, 2013, p. 264).

\section{CONCLUSIONES}

1. La incorporación de los derechos humanos en el sistema procesal constitucional mexicano ha marcado un impacto de gran dimensión, pues a partir de su incorporación al derecho procesal constitucional mexicano trajo consigo grandes cambios de paradigma. En ese sentido, el Estado mexicano a fin de cumplir con las obligaciones que ha adquirido debe desarrollar una sus principales funciones como Estado, que es la de administrar justicia.

2. El sistema por medio del cual se lleva a cabo el control de la constitucionalidad es el concentrado básicamente, ya que en este tipo de sistema se confía el control constitucional a un solo órgano, un Tribunal Constitucional, el cual es el encargado de resolver los conflictos que se presentan al confrontar el texto de una ley con el de la Constitución, a efecto de determinar si la ley es acorde con esta. Por ello, los tribunales ordinarios carecen de facultades para poder inaplicar una ley o simplemente para juzgar esta ley o determinar que es contraria a la Constitución. Aunque debe resaltarse que hoy en día se cuenta con matices del sistema difuso, en el que todos los órganos jurisdiccionales pueden conocer sobre la constitucionalidad de normas, esto a consecuencia de la convencionalidad.

Ahora bien, hasta este respecto se puntualiza que México cuenta esencialmente con un sistema concentrado de constitucionalidad y que es otorgado al Poder Judicial de la Federación, por lo tanto, solo este puede declarar la inconstitucionalidad de las normas, a través de las garantías antes mencionadas; en consecuencia, el nivel de especialización de dichos órganos es mayor que el nivel que podría atribuirse a un órgano jurisdiccional ordinario, sin demeritar en ningún momento su función.

3. Otro punto que es necesario resaltar es el referente al lugar que ocupan los tratados internacionales en el Sistema Jurídico Mexicano. Y que por supuesto resulta de vital importancia al momento de resolver un caso concreto, pues resulta indispensable respetar siempre la supremacía constitucional, entendida como 
la cualidad que tiene la Constitución de ser la norma que funda y da validez a la totalidad del ordenamiento jurídico de cualquier país.

4. Ahora bien, tomando en consideración que se concibió a los derechos humanos como el conjunto de atribuciones reconocidas en los instrumentos internacionales y en las constituciones para hacer efectiva la idea de la dignidad de todas las personas y en consecuencia que puedan conducir una existencia realmente humana desde los ámbitos más diversos. Debe tenerse presente que de dicha definición se puede deducir la importancia y trascendencia de hacer efectiva la protección a estos derechos.

5. En cuanto a la reforma constitucional del 11 de junio de 2011 se puede decir que fue evidente el cambio de paradigma, ya que significó una reinterpretación de normas adjetivas como sustantivas, además de que se precisó la separación que se hace de los derechos y sus garantías, esto por que tradicionalmente se había asociado con ambos y hasta de alguna forma confundido unos con otros, cuando ya se ha visto que las garantías serán aquellos remedios procesales por medio de los cuales las personas harán respetar sus derechos.

De esta forma, en el párrafo segundo se recoge la figura de la "interpretación conforme", al señalarse que todas las normas relativas a derechos humanos se deberán interpretar a la luz de la protección constitucional y de los tratados internacionales. Lo cual resulta ser una guía para los aplicadores de las normas jurídicas, además de que se invoca el denominado principio pro persona. Que supone que cuando existan distintas interpretaciones posibles respecto de una norma jurídica se deberá elegir aquella que más proteja al titular de un derecho humano, lo que como se ha reiterado sirve de parámetro de aplicación.

En síntesis, en el tercer párrafo se revelaron en esencia tres problemas a los que México se enfrenta: a) el señalamiento de las obligaciones, a cargo de todas las autoridades del Estado mexicano, de promover, proteger, respetar y garantizar los derechos; b) el referente a los principios de interdependencia indivisibilidad y progresividad que se han mencionado; y c) se refiriere a lo que debe hacer el Estado mexicano cuando se presenten violaciones de derechos, es decir, prevenir, investigar, sancionar y reparar.

Lo que paso a paso se ha ido realizando, pues a través de los diversos criterios se han establecido las obligaciones de las autoridades, ya que de forma clara la Corte ha indicado que todas las autoridades tienen la obligación de proteger y respetar los derechos humanos, sin embargo, en cuanto a la garantía de esto se piensa que continua la laguna en la ley, pues solo se han dictado los pasos para llevar a cabo la interpretación, que a través de la cual se realizará la protección de estos. Y en cuanto al último punto aún se está en vías de su realización.

6. El control de convencionalidad no es otra cosa más que revisar la adecuación de la norma o de la conducta a la convención, tal como se haría con el control de constitucionalidad, la diferencia es que en el control de convencionalidad el ajuste se hace frente a una convención con la finalidad de garantizar la eficacia del tratado en los casos en que las leyes sean contrarias a la convención. 
Además, este control debe ejercer ex officio, es decir, sin necesidad de que las partes lo soliciten y dentro de las competencias y regulaciones procesales correspondientes de cada autoridad. Y los órganos facultados para ejercerlo son todas las autoridades del país que en el ámbito de sus competencias tienen la obligación de aplicar las normas correspondientes, haciendo la interpretación más favorable a la persona para lograr su protección, lo cual se realiza a través del sistema difuso.

O sea, el sistema de control constitucional se realiza mediante el sistema concentrado, en tanto el control convencional por el sistema difuso, pero hasta este momento no existen instrumentos de técnica jurídica como en el control constitucional para efectivizar su cumplimiento, pues no se ha establecido en la Constitución y mucho menos en la legislación de menor jerarquía, algún instrumento que realice esa función, sino que únicamente se lleva a cabo la aplicación de este control a través de la interpretación de acuerdo con la relación en el principio pro persona, que en un momento dado permite la inaplicación de la norma en beneficio del afectado con la norma.

De lo anterior, se colige que si bien el poder judicial y en concreto el poder judicial de la Federación ha realizado muchas acciones encaminadas a cumplir con las cuatro sentencias condenatorias para el Estado mexicano, en cuanto al control de convencionalidad, tales como: cursos de actualización y capacitación, manuales de aplicación del control, protocolos de actuación en diversos casos, la emisión de criterios que permiten determinar el parámetro de aplicación del control, por mencionar algunos.

Lo cierto es que ello no termina de generar la seguridad jurídica que en todo procedimiento debe prevalecer, pues finalmente la interpretación se deja al arbitrio del juzgador y que si bien está obligado a fundar y motivar su resolución, lo cierto es que el criterio aplicado en la solución de un asunto puede no abordarse desde la misma reflexión para la solución de otro, aunque se tuvieran las mismas características. Por lo tanto, ahí también surge la necesidad de armonizar los criterios y en su caso poder lograr el tan mencionado ius communne.

Sin mencionar además la economía del tiempo y la efectivización de la protección de los derechos humanos, haciéndose cumplir en su esplendor los principios que rigen a estos y armonizarlos con la Constitución.

7. Se puede agregar que al realizar un pequeño comparativo con los mecanismo de control que México tiene incorporados a su Sistema de Control Constitucional se puede decir que el recurso de inconstitucionalidad europeo se parece a las acciones de inconstitucionalidad, solo en cuanto a que tratan de revisar una norma en abstracto y la acción debe presentarse dentro de los 30 días naturales contados a partir de la fecha de publicación de la norma, y en cuanto a que se trata de proteger a la Constitución, pero con la cuestión de inconstitucionalidad no existe ninguna similitud respecto de los demás mecanismo, pues si bien el juicio de amparo se realiza en defensa concreta de la Constitución tiene un funcionamiento en el sistema concentrado y se realiza a instancia de parte. 
8. No existe todavía un mecanismo de control de convencionalidad al respecto, aun cuando la propia Constitución lo establece, por lo que es factible la incorporación de un mecanismo de cuestión de inconvencionalidad que se aplicará de forma directa a los juzgadores sobre el control de la convención respecto de la norma.

\section{PROPUESTA}

Consecuentemente se concluye que no existe todavía un mecanismo de control al respecto, aunque la propia Constitución lo establece, por lo que se cree que el mencionado mecanismo podría funcionar del modo siguiente:

a. En primer término tendría que crearse la norma reglamentaria del artículo $1^{\circ}$ Constitucional, pues ahí el legislador ya prevé la existencia de garantías para la protección de los derechos humanos.

b. En la mencionada norma reglamentaria deberá indicarse como en toda norma, cuál es la procedencia del instrumento, que en este caso sería en forma de una cuestión de inconvencionalidad.

c. La cuestión de inconvencionalidad, como podría denominarse, sería un mecanismo de forma directa que aplicarían los juzgadores sobre el control de la convención respecto de la norma. Por lo que en primer término debe realizarse la interpretación de acuerdo con los pasos que hasta el momento la Corte ha indicado en diversos criterios. Y si de dicha interpretación resulta que lo conveniente es la inaplicación de la norma, y dicha norma afecte en gran medida a las partes del procedimiento por resolver, se deberá remitir al órgano especializado en el control de la convencionalidad.

d. Este mecanismo debe funcionar de oficio para economizar tiempos, pero dando vista a las partes.

e. Su tramitación sería en forma incidental, con un plazo determinado para resolver, pues con esto no se estaría en la inseguridad de que se resuelva de forma tardía.

f. Los efectos de la resolución serían erga omnes para cumplir con el objeto de armonizar los criterios, y su resolución se publicaría en forma de criterios jurisprudenciales. Y en caso de que llegara a existir alguna contradicción no habría mayor problema, puesto que recuérdese que hoy en día existen los plenos de circuito para armonizar la jurisprudencia.

g. El conocimiento de la cuestión por razón de técnica y mayor dominio sería el poder judicial de la Federación.

h. En caso de que resultara procedente la cuestión de convencionalidad, se tendría que inaplicar la norma, en caso contrario, se aplicaría la norma. 


\section{REFERENCIAS}

Barrena, N., Montemayor, G., y Romo De Vivar, C. (2001). Incorporación del derecho internacional en la Constitución mexicana. En R. Gutiérrez Rivas (Coord.). Derechos humanos. Memoria del IV Congreso Nacional de Derecho Constitucional. México: UNAM.

Carbonell, M. (2012a). Introducción al control de convencionalidad. México: UNAM.

Carbonell, M. (2012b). Los derechos humanos en México durante el siglo XX: notas para su estudio. Revista Mexicana de Historia de Derecho, vol. XXVI, 121-145. México: UNAM.

Carpizo, J. (jul.-dic., 2011). Los derechos humanos: naturaleza denominación y características. Revista Mexicana de Derecho Constitucional, 25. México: UNAM.

Castellá, A. J. M., Expósito, E. (1999). La intervención de las partes del juicio A Quo en la cuestión de inconstitucionalidad. El artículo 37.2 LOCT y la incidencia de la STEDH de 23 de junio de 1993. Universidad Nacional de Educación a Distancia (Comp.). Teoría y Realidad Constitucional, 4, 293-316. Madrid, España: Editorial Centro de Estudios Ramón Areces, S.A.

Declaración y Programa de Acción (1993). Conferencia Mundial de Derechos Humanos. Celebrada en Viena. Recuperado de http://daccess-ddsny.un.org/doc/ UNDOC/GEN/G93/142/36/PDF/G9314236.pdf?OpenElement

Ferrer, E. (2012). Interpretación conforme y control de convencionalidad, el nuevo paradigma del juez mexicano. México: UNAM.

Ferrer, E., Sánchez, R. (2013). Control difuso de constitucionalidad y convencionalidad. México: CDHDF, Suprema Corte de Justicia de la Nación, Naciones Unidas, Derechos Humanos, Oficina del Alto Comisionado.

Gozaíni, O. A. (2000). El derecho procesal constitucional y los derechos humanos (vínculos y autonomías). México: UNAM.

Guerrero, H. F., Solórzano, M. A. (2012). Incorporación del derecho internacional de los derechos humanos al Sistema Jurídico Mexicano. México: Comisión Mexicana de Defensa y Promoción de los Derechos Humanos, AC.

Martínez, V. M. (1998). Los derechos humanos en el siglo XX. Cuadernos Constitucionales, 3. México, Centroamérica: Universidad Nacional Autónoma de México, Corte de Constitucionalidad de Guatemala.

Silva, F. (2013). Control de convencionalidad y constitucionalidad ex oficio: Condiciones de racionalidad para su ejercicio en el juicio de amparo. Revista del Instituto de la Judicatura Federal, 6, 91-101.

Vásquez, L. D., Serrano, S. (2011). Los principios de universalidad, interdependencia. Indivisibilidad y progresividad, apuntes para su aplicación práctica. México: UNAM. 